\title{
Brain glutamate and $y$-aminobutyrate (GABA) metabolism in thiamin-deficient rats
}

\author{
BY MARTYN G. PAGE*, VICTOR ANKOMA-SEY†, WILLIAM F. COULSON \\ AND DAVID A. BENDER \\ Department of Biochemistry, University College and Middlesex School of Medicine, \\ University College London, Gower Street, London WC1E 6BT
}

(Received 2 February 1989-Accepted 29 March 1989)

\begin{abstract}
The brain metabolism of glutamate and $\gamma$-aminobutyrate (GABA) was investigated in thiamin-deficient and pair-fed control rats, in order to determine whether the GABA shunt may provide an important alternative to 2-oxo-glutarate dehydrogenase $(E C$ 1.2.4.2) in energy-yielding metabolism in thiamin deficiency. Brains from thiamin-deficient animals contained less glutamate, 2-oxo-glutarate and GABA than those from control animals. The brain content of ATP was unaffected by thiamin deficiency. After intracerebroventricular injection of ${ }^{14} \mathrm{C}$ lglutamate, the specific radioactivity of GABA in the brains from deficient animals was $45-50 \%$ higher than that in controls, suggesting a considerable increase in the metabolic flux through the GABA shunt in thiamin deficiency. Brain GABA showed a marked circumannual variation, with a peak in mid-summer and a minimum value in mid-winter.
\end{abstract}

$\gamma$-Aminobutyrate: Brain glutamate: GABA: Thiamin deficiency: Rat

Thiamin has a central role in energy-yielding metabolism. Thiamin pyrophosphate is the coenzyme for pyruvate dehydrogenase $(E C 1.2 .4 .1)$, 2-oxo-glutarate dehydrogenase $(E C$ 1.2.4.2) and transketolase $(E C 2.2 .1 .1)$, and hence thiamin deficiency results in a considerable impairment of both carbohydrate metabolism, by way of glycolysis and the pentose phosphate pathway, and general energy-yielding metabolism, by way of the citric acid cycle (Holowack et al. 1968; Collins et al. 1970). Deficiency affects especially the nervous system, which is largely dependent on glucose metabolism. In the Far East, chronic thiamin insufficiency results in peripheral nervous system damage, dry beriberi, whereas in Western countries thiamin deficiency (associated with alcohol and opiate abuse) results in central nervous system damage, the Wernicke-Korsakoff syndrome.

Both the time course of the development of neurological signs and the anatomical location of brain lesions in thiamin-deficient experimental animals are poorly correlated with the impairment of pyruvate dehydrogenase, and show a better correlation with impairment of transketolase (Dreyfus \& Hauser, 1965). However, there is a considerable excess of transketolase activity compared with other enzymes of the pentose phosphate pathway, and it is unlikely that even under conditions of severe thiamin deficiency that transketolase would be a rate-limiting step in carbohydrate metabolism (McCandless et al. 1976).

Despite the impairment of energy-yielding metabolism, there is no change in the brain content of ATP in thiamin deficiency (Holowack et al. 1968; McCandless \& Schenker, 1968). While this might reflect simply an excess of 2-oxo-glutarate dehydrogenase activity, as is the case for transketolase, it is also possible that there may be an alternative pathway for the conversion of 2-oxo-glutarate to succinate.

Present addresses: * St Joseph's College, Oxford OX4 2UJ. † Ghana Medical School, Korle Bu, Accra, Ghana. $\ddagger$ For reprints. 


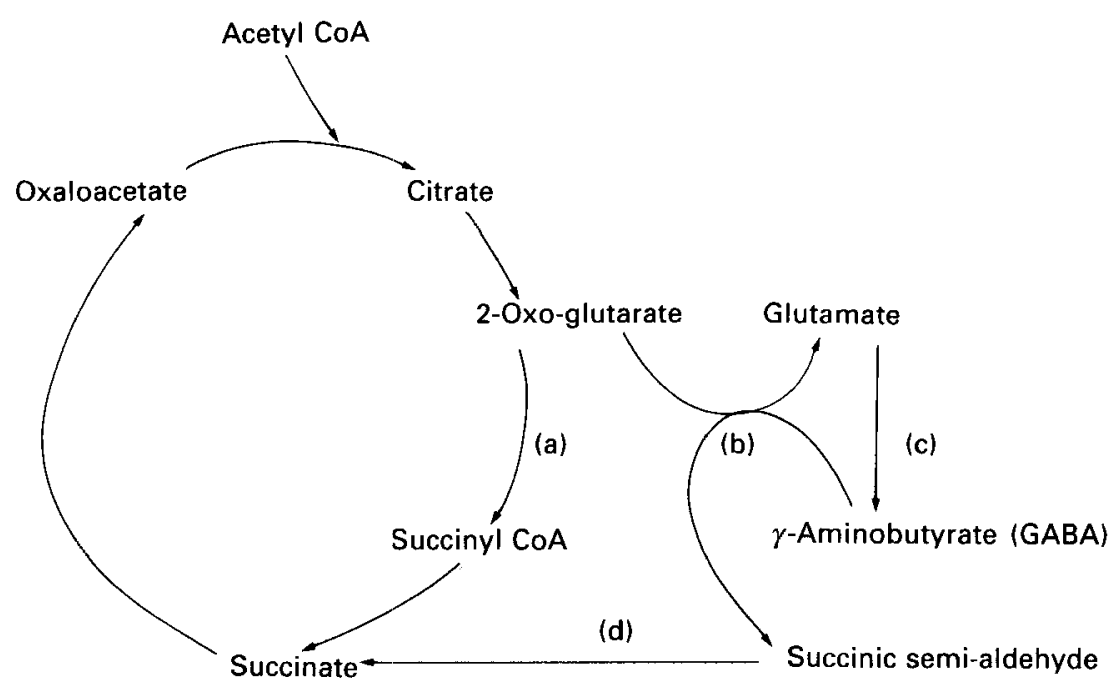

Fig. 1. The GABA shunt and tricarboxylic acid cycle. (a), 2-Oxo-glutarate dehydrogenase (EC 1.2.4.2); (b), GABA aminotransferase (EC 2.6.1.19) and other aminotransferases, glutamate dehydrogenase $(E C$ 1.4.1.2); (c), glutamate decarboxylase (EC 4.1.1.15); (d), succinic semi-aldehyde dehydrogenase $(E C$ 1.2.1.24).

The neurotransmitter $\gamma$-aminobutyrate (GABA) is synthesized by decarboxylation of glutamate (which arises by transamination or reductive amination of 2-oxo-glutarate), and is in turn catabolized by transamination to succinic semialdehyde and oxidation to succinate. This pathway (shown in Fig. 1) has been termed the GABA shunt; in addition to its role in synthesizing and catabolizing the neurotransmitter, it is possible that the GABA shunt plays a role in energy-yielding metabolism.

The present study was designed in order to determine whether the GABA shunt may provide a significant alternative to 2-oxo-glutarate dehydrogenase in thiamin deficiency, by-passing this thiamin-dependent step in the tricarboxylic acid cycle.

\section{METHODS}

Animals and diets

Male Wistar rats were maintained for up to 4 weeks from weaning on a high-carbohydrate, thiamin-free diet containing $(\mathrm{g} / \mathrm{kg})$ : maize starch 547 , sucrose 200 , vitamin-free casein 140 , gelatine 60 , mineral salt mix 41 , maize oil 10 and vitamin mix 2 . Vitamins $A, D, E$ and $K$ were dissolved in the maize oil, to provide $(\mathrm{mg} / \mathrm{kg}$ diet $)$ : retinol palmitate 10 , calciferol $3 \mu \mathrm{g}$, menaphthone 1 and $\alpha$-tocopheryl acetate 75 . The vitamin mixture provided $(\mathrm{mg} / \mathrm{kg}$ diet) : riboflavin 10 , nicotinamide 15 , pyridoxine hydrochloride 5 , biotin 1 , folic acid 5 , vitamin $\mathrm{B}_{12} 50 \mu \mathrm{g}$, calcium pantothenate 40 , choline bitartrate 1800 . The mineral salt mixture provided $\left(\mathrm{g} / \mathrm{kg}\right.$ diet): $\mathrm{CaHPO}_{4} 18 \cdot 1, \mathrm{KCl} 8 \cdot 2, \mathrm{Na}_{2} \mathrm{HPO}_{4} 7 \cdot 4, \mathrm{CaCO}_{3} 4 \cdot 5$, $\mathrm{MgSO}_{4} \cdot \mathrm{H}_{2} \mathrm{O} 2 \cdot 8, \mathrm{ZnCO}_{3} 30 \mathrm{mg}, \mathrm{CuSO}_{4} \cdot 5 \mathrm{H}_{2} \mathrm{O} 23 \cdot 5 \mathrm{mg}, \mathrm{MnSO}_{4} \cdot 4 \mathrm{H}_{2} \mathrm{O} 18 \mathrm{mg}$, ferric citrate pentahydrate $18 \mathrm{mg}, \mathrm{KIO}_{3} 1 \mathrm{mg}$. The dry ingredients, except the gelatin, were mixed together with the maize oil, then the gelatine was dissolved in $600 \mathrm{ml}$ hot water $/ \mathrm{kg}$ diet and mixed with the dry ingredients. On cooling, the diet set to a firm jelly which was cut into cubes, frozen and stored at $-20^{\circ}$ until required.

Animals were maintained in groups of five per cage, on wire grids to minimize coprophagy. Animals fed on the thiamin-free diet were allowed access to food ad lib. Control animals received the same diet, supplemented with $10 \mathrm{mg}$ thiamin hydro- 
chloride/ $\mathrm{kg}$ diet, and were pair-fed with the experimental group, each group receiving the same amount of food as an age-matched experimental group had consumed the day before. Animals receiving the stock diet were fed on Diet 86 (A. Dixon \& Sons, Ware, Herts) ad lib. All animals had free access to water at all times. There was no control of day-length; the animal house was illuminated by a mixture of daylight and artificial light during the working day.

Animals were killed by decapitation using a small-animal guillotine. Blood was collected into heparinized beakers on ice and centrifuged at $2000 \mathrm{~g}$ for $15 \mathrm{~min}$. The erythrocyte pellet was washed by resuspension twice in the original blood volume of 0.15 mol sodium chloride/ 1 , then lysed by suspension in the same volume of distilled water and frozen and stored for up to 1 week at $-20^{\circ}$, until required for the determination of transketolase, as described later. In all cases, samples from deficient and control animals at the same timepoint had been stored for the same length of time, and were analysed together. The brains were dissected out within $20 \mathrm{~s}$ of decapitation, frozen in liquid nitrogen and stored at $-20^{\circ}$ until required for the determination of ATP, glutamate, 2-oxo-glutarate, GABA and thiamin, as described later. A portion of liver was dissected out within $45 \mathrm{~s}$ of decapitation, was frozen in liquid $\mathrm{N}_{2}$ and stored at $-20^{\circ}$ until required for the determination of thiamin.

\section{In vivo studies of brain glutamate metabolism}

Animals which had been maintained on the diets for 3 weeks from weaning were anaesthetized by intra-muscular injection of Hypnorm (fluanisone $10 \mathrm{mg}$ and fentanyl citrate $0 \cdot 135 \mathrm{mg} / \mathrm{kg}$ body-weight; Janssen). The skin over the skull was slit along the midline, from between the eyes to the level of the ears with a scalpel and peeled aside to reveal the skull. A hole was drilled through the skull using a $2 \mathrm{~mm}$ diameter needle at a position $5 \mathrm{~mm}$ posterior to the coronal suture and $2 \mathrm{~mm}$ to the left of the saggital (mid-line) suture. A solution $(10 \mu \mathrm{l})$ of $\mathrm{L}-\left[\mathrm{U}^{14}\right]$ glutamate $(50 \mu \mathrm{Ci} / \mathrm{ml}, 280 \mathrm{Ci} / \mathrm{mol})$ was then injected through this hole, using a Hamilton micro-syringe with a needle sharpened at an angle of $45^{\circ}$, with a plastic sleeve over the needle to prevent penetration further than $3 \mathrm{~mm}$ (Waynforth, 1980).

At 2, 5 and $10 \mathrm{~min}$ after the intracerebroventricular injection, animals were decapitated, brains were dissected out and frozen in liquid $\mathrm{N}_{2}$, within $20 \mathrm{~s}$. Brain GABA and radioactivity in GABA were determined as described later.

\section{Analytical methods}

Frozen brains were bisected longitudinally. Half was homogenized while still frozen in $10 \mathrm{~m} 1$ ice-cold $80 \%$ (by volume) ethanol/g tissue, followed by centrifugation at $25000 \mathrm{~g}$ for 25 min. The resulting supernatant fraction was used for the fluorimetric determination of GABA after chromatographic separation on columns of Sepharose C16B and reaction with $o$-phthalaldehyde (van der Heyden \& Korf, 1978; van der Heyden et al. 1979).

The other half of each brain was homogenized while still frozen in $10 \mathrm{ml}$ ice-cold perchloric acid $(0.4 \mathrm{~mol} / \mathrm{l}) / \mathrm{g}$ tissue, followed by centrifugation at $25000 \mathrm{~g}$ for $30 \mathrm{~min}$. The supernatant fraction was neutralized with potassium hydroxide $(0.4 \mathrm{~mol} / 1)$ and $1 \mathrm{ml}$ triscitrate buffer $(1 \mathrm{~mol} / \mathrm{l})$ at $\mathrm{pH} 7 \cdot 3$, cooled to $4^{\circ}$ and centrifuged at $2000 \mathrm{~g}$ for $20 \mathrm{~min}$ to remove potassium perchlorate. Portions of this neutralized acid extract were used for the determination of total thiamin, after acid phosphatase (EC 3.1.3.2) action to hydrolyse phosphates to free thiamin, by the thiochrome fluorimetric method (Udenfriend, 1962); glutamate and 2-oxo-glutarate spectrophometrically using glutamate dehydrogenase (EC 1.4.1.2) (Bergmeyer \& Bernt, 1974), and ATP spectrophometrically by the linked reaction of phosphoglycerate kinase (EC 2.7.2.3) and glyceraldehyde 3-phosphate dehydrogenase (EC 1.2.1.12) (Jaworek et al. 1974).

For the studies of $\left[{ }^{14} \mathrm{C}\right]$ glutamate metabolism in vivo, the entire brain was homogenized 


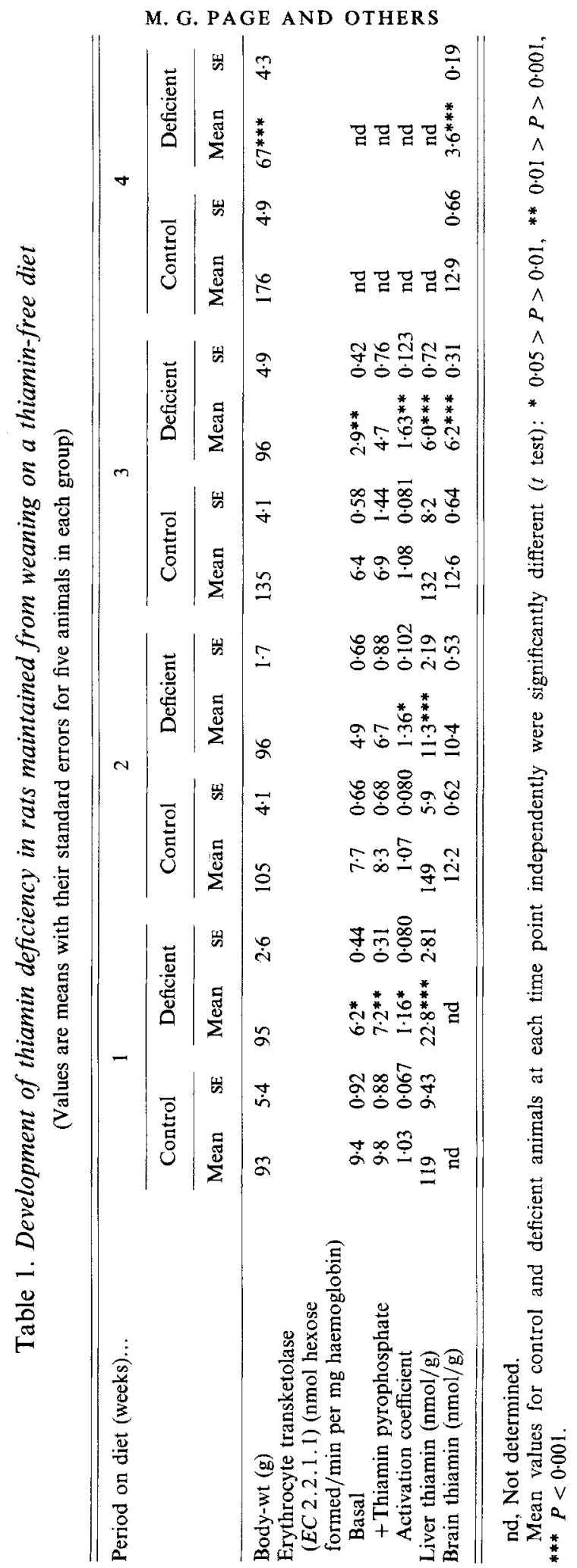


Table 2. Brain ATP, glutamate, 2-oxo-glutarate and $\gamma$-aminobutyrate $(G A B A)$ in rats maintained for 3 weeks from weaning on a thiamin-free diet

(Values are means with their standard errors for numbers of animals as shown)

\begin{tabular}{|c|c|c|c|c|c|c|}
\hline & \multicolumn{3}{|c|}{ Control } & \multicolumn{3}{|c|}{ Thiamin-free diet } \\
\hline & Mean & $\mathbf{S E}$ & $n$ & Mean & SE & $n$ \\
\hline $\mathrm{ATP}(\mu \mathrm{mol} / \mathrm{g})$ & $2 \cdot 8$ & 0.085 & 16 & $2 \cdot 9$ & $0 \cdot 009$ & 17 \\
\hline Glutamate $(\mu \mathrm{mol} / \mathrm{g})$ & $13 \cdot 8$ & $0 \cdot 29$ & 55 & $11 \cdot 3$ & $0 \cdot 21 * * *$ & 61 \\
\hline 2-Oxo-glutarate $(\mu \mathrm{mol} / \mathrm{g})$ & 0.14 & 0.006 & 23 & 0.09 & $0.007^{* * *}$ & 21 \\
\hline $\mathrm{GABA}(\mu \mathrm{mol} / \mathrm{g})$ & 1.67 & 0.046 & 17 & $1 \cdot 58$ & $0 \cdot 031^{* *}$ & 17 \\
\hline
\end{tabular}

Mean values were significantly different from those of the control group ( $t$ test): ${ }^{* *} 0 \cdot 01>P>0 \cdot 001$, *** $P<0.001$.

in $80 \%$ (by volume) ethanol. GABA was determined as described previously. Radioactivity in GABA was determined after evaporating replicate $1 \mathrm{ml}$ samples of the supernatant fraction to dryness, redissolving in $100 \mu \mathrm{l} 50 \%$ (by volume) acetic acid, containing glutamate $(1 \mathrm{mmol} / 1)$ and GABA $(1 \mathrm{mmol} / 1)$, and paper chromatography of $50 \mu 1$ portions, developed in ascending $7 \mathrm{vol} .95 \%$ (by volume) ethanol: $3 \mathrm{vol}$. ammonium acetate $(0.1 \mathrm{~mol} / \mathrm{l}), \mathrm{pH} 5.0$. Parallel standards of glutamate and GABA were also chromatographed, and their positions determined by staining with ninhydrin. Regions of the chromatograms containing glutamate and GABA were excised, placed in scintillation counter vials with $2 \mathrm{ml}$ of a solution of PPO (2.5 g/l) and POPOP $(0.25 \mathrm{~g} / 1)$ in toluene, and radioactivity determined in a Beckman liquid scintillation spectrometer.

The activity of transketolase in erythrocyte lysates was determined colorimetrically, with and without pre-incubation of the sample with thiamin pyrophosphate $(20 \mathrm{mmol} / \mathrm{l})$, as described by Brin (1967). Haemoglobin was determined colorimetrically by the cyanmethaemoglobin method (Oser, 1965). Enzyme activity was calculated as nmol hexose formed/min per mg haemoglobin, and also as the activation coefficient (ratio: activity after pre-incubation with thiamin pyrophosphate: basal activity).

\section{RESULTS}

The animals fed on the thiamin-free diet grew at the same rate as the controls during the first week after weaning; thereafter, as shown in Table 1, they gained no more weight, and during the fourth week lost $30 \%$ of their body-weight. At this time they showed signs of neurological damage, with arched spines and an unsteady gait.

Both basal and thiamin pyrophosphate-stimulated transketolase activity in erythrocyte lysates were lower in thiamin-deficient animals than in controls; the transketolase activation coefficient was significantly higher in the deficient animals. Liver total thiamin was considerably lower in deficient animals than in controls from the first week. Brain thiamin was apparently protected, not showing any significant fall until the third week, when it was $48 \%$ of that in control animals. By the fourth week, brain thiamin in the deficient animals was only $28 \%$ that of controls.

As shown in Table 2, maintaining the animals for 3 weeks on the thiamin-deficient diet had no effect on brain ATP, but resulted in a small but significant fall in the brain concentrations of glutamate, 2-oxo-glutarate and GABA. The specific radioactivity of GABA formed after intracerebroventricular injection of $\left[{ }^{14} \mathrm{C}\right]$ glutamate (shown in Table 3) was significantly higher in the thiamin-deficient animals at 2, 5 and $10 \mathrm{~min}$ after injection. 
Table 3. Brain $\gamma$-aminobutyrate $(G A B A)$ and specific radioactivity in $G A B A$ after intracerebroventricular injection of $0.5 \mu \mathrm{Ci}\left[U-{ }^{14} \mathrm{C}\right]$ glutamate, in rats maintained for 3 weeks from weaning on a thiamin-free diet

(Values are means with their standard errors for numbers of animals as shown)

\begin{tabular}{|c|c|c|c|c|c|c|c|}
\hline \multirow{2}{*}{\multicolumn{2}{|c|}{ Period after injection (min) }} & \multicolumn{3}{|c|}{ Control } & \multicolumn{3}{|c|}{ Thiamin-free diet } \\
\hline & & Mean & $\mathrm{SE}$ & $n$ & Mean & $\mathrm{SE}$ & $n$ \\
\hline \multirow[t]{2}{*}{2} & $\mathrm{GABA}(\mu \mathrm{mol} / \mathrm{g})$ & 1.57 & 0.087 & 10 & $I \cdot 34^{*}$ & 0.063 & 8 \\
\hline & Specific activity $(\mathrm{Ci} / \mathrm{mol})$ & 105 & 8.98 & 10 & $152 * *$ & $10 \cdot 1$ & 8 \\
\hline \multirow[t]{2}{*}{5} & GABA $(\mu \mathrm{mol} / \mathrm{g})$ & $2 \cdot 18$ & $0 \cdot 015$ & 12 & $1.59 * *$ & $0-038$ & 6 \\
\hline & Specific activity $(\mathrm{Ci} / \mathrm{mol})$ & 127 & $10 \cdot 9$ & 12 & $192 * *$ & $10 \cdot 0$ & 6 \\
\hline \multirow[t]{2}{*}{10} & $\mathrm{GABA}(\mu \mathrm{mol} / \mathrm{g})$ & $2 \cdot 32$ & $0 \cdot 120$ & 7 & $2 \cdot 05^{*}$ & 0.057 & 7 \\
\hline & Specific activity $(\mathrm{Ci} / \mathrm{mol})$ & 61 & $5 \cdot 1$ & 7 & $89^{* *}$ & $9 \cdot 5$ & 7 \\
\hline
\end{tabular}

Mean values for control and deficient animals at each time point independently were significantly different $\left(t\right.$ test): ${ }^{*} 0.05>P>0.01, * * 0.01>P>0.001$.

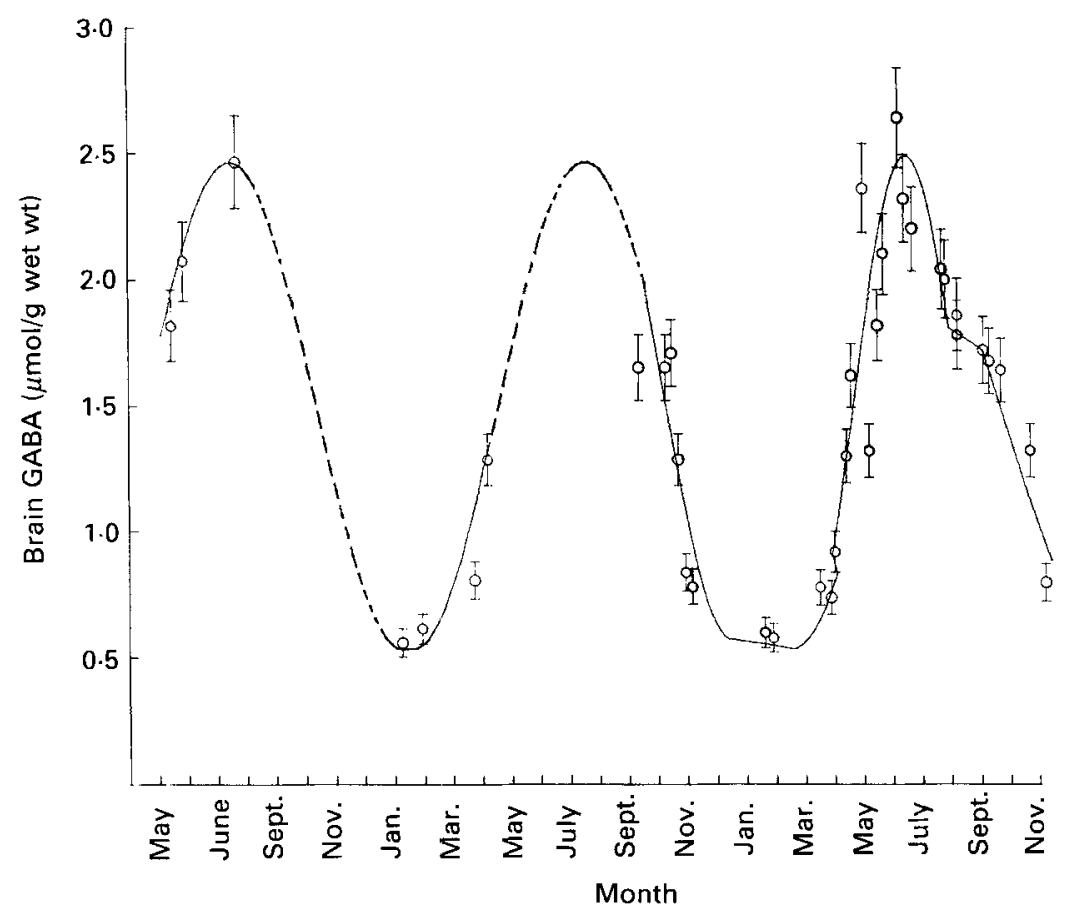

Fig. 2. Circumannual variation in brain $\gamma$-aminobutyrate (GABA) in 100-g male rats maintained on animal-house stock diet. Points show means with their standard errors for three to six animals in each group. - - , Interpolation.

During the course of the present study it was noted that while there was a consistent and significant reduction in brain GABA in thiamin-deficient animals compared with controls, there was a greater difference between groups of animals in which brain GABA was measured at different time intervals than between deficient and control animals investigated at the same time interval. The brain content of GABA was, therefore, determined in groups 
of three to six male rats, weighing $100 \mathrm{~g}$, which had been maintained from weaning on animal house stock diet, at intervals over 3 years. The results are shown in Fig. 2, which shows a clear and marked circumannual variation in brain GABA, with a peak of 2.5 (SE 0.17) $\mu \mathrm{mol} / \mathrm{g}$ tissue in mid-summer and a minimum concentration of 0.6 (SE 0.04) $\mu \mathrm{mol} / \mathrm{g}$ tissue in mid-winter.

\section{DISCUSSION}

The results in Table 1 show that maintenance for 3-4 weeks on a thiamin-free diet resulted in a significant degree of thiamin depletion, with a fall in the brain concentration of thiamin to $28 \%$ of that found in pair-fed control animals by the fourth week.

In common with previous studies, which have demonstrated considerable impairment of energy-yielding metabolism at the levels of pyruvate decarboxylase, transketolase and 2-oxo-glutarate decarboxylase (Holowack et al. 1968; McCandless \& Schenker, 1968), the present study has shown that moderately severe thiamin deficiency has no effect on the concentration of ATP in the brain. Similarly, the reduction in the brain concentration of GABA, to $90 \%$ of the control value, is in agreement with other reports (Gubler et al. 1974; Hamel et al. 1979; Butterworth, 1983).

Impairment of 2-oxo-glutarate decarboxylase in thiamin deficiency, reported by Holowack et al. (1968), Gibson et al. (1984) and Parker et al. (1984) to be of the order of $50 \%$, would be expected to result in an increased accumulation of 2-oxo-glutarate in the brain. As shown in Table 2, there was however a significant reduction in brain 2-oxoglutarate, to about $64 \%$ of the control level.

As shown in Table 3 , there was a significant increase in the specific activity of GABA formed from intracerebroventricularly injected $\left[{ }^{14} \mathrm{C}\right]$ glutamate in the thiamin-deficient animals. A part of this might be attributed to the reduced pool of brain glutamate, since all animals received the same amount of radioactivity $(0.5 \mu \mathrm{Ci})$. However, thiamin deficiency had no significant effect on the weight of the brain, and there was no difference between the two groups of animals in the total radioactivity recovered/g of brain (values not shown). While the brain concentration of glutamate in the deficient animals was reduced by $18 \%$ compared with controls, the specific activity of GABA was increased by between 45 and $50 \%$. The increase in the brain content of GABA after the intracerebroventricular injection (presumably a response to either the anaesthetic or the trauma of injection) was the same in both groups of animals. The results thus suggest that there was an increase in the rate of synthesis of GABA, and hence an increase in metabolic flux through the GABA shunt, in the thiamin-deficient animals. A similar increase in flux thorough the GABA shunt in thiamin-deficient animals can be calculated from the results reported by Gubler et al. (1974). While it might, therefore, be expected that the specific radioactivity of brain GABA would reach a peak earlier in the thiamin-deficient animals, with only three time points (see Table 3 ) it is not possible to determine rate curves.

It is difficult to account for the observed reduction in brain 2-oxo-glutarate in the deficient animals, to $64 \%$ of that in the controls. Impairment of 2-oxo-glutarate dehydrogenase in thiamin deficiency, reported by Holowack et al. (1968), Gibson et al. (1984) and Parker et al. (1984) to be of the order of $50 \%$, would be expected to result in increased accumulation of 2-oxo-glutarate in the brain. 2-Oxo-glutarate is the preferred oxo-acid substrate of GABA aminotransferase (EC 2.6.1.19), and in vitro the activity of the GABA shunt can be manipulated by altering the concentration of 2-oxo-glutarate (McKhann \& Towers, 1961; Schousboe, 1981). It is likely that increased activity of this enzyme, coupled with increased activity of succinic semi-aldehyde dehydrogenase (EC 1.2.1.24), would result in increased amination of 2-oxo-glutarate to glutamate. At 
the same time, the increased catabolism of GABA would relieve product inhibition of glutamate decarboxylase $(E C 4.1 .1 .15)$, thus resulting in increased synthesis and catabolism of GABA, an increased rate of metabolic flux through the GABA shunt (Hearl \& Churchich, 1984; Porter \& Martin, 1984; Porter et al. 1986).

The marked circumannual variation in brain GABA, shown in Fig. 2, appears not to have been reported previously, although Rozanov (1982) has reported that in mice the brain GABA concentration is higher in winter than in summer, the reverse of the pattern reported here in rats. In reviewing circadian rhythms in neurotransmitter receptors, Wirz-Justice (1987) noted that all receptors that have been investigated show circadian rhythms, and the phase and amplitude of these rhythms often show circumannual variation, even in animals maintained under conditions of controlled day-length. Such circumannual effects are reported to vary widely between species, between different strains of the same species, and even between different breeding colonies of the same species (Wirz-Justice, 1987). In the present study there was no control of day-length; the animals were exposed to varying natural light, as well as artificial light during the working day. The animals were Wistar rats from a breeding colony maintained in the Courtauld Institute of Biochemistry of the Middlesex Hospital Medical School, into which there had been no introductions for many years. All animals were killed at about the same time of day, between 09.30 and 11.00 hours.

The studies reported in Tables 2 and 3 were all performed between February-April and September-November, equivalent periods in the circumannual variation in brain GABA shown in Fig. 2. Similar studies were performed at other times of the year. Although the results showed a significantly different concentration of GABA in the brains of control animals, as would be expected from the circumannual variation shown in Fig. 2, there was consistently a significant difference between thiamin-deficient and control animals, of the same order of magnitude as that shown in Table 2.

The present study has thus demonstrated that in thiamin deficiency there is an apparent increase in the rate of synthesis of GABA from glutamate, indicative of an increased rate of metabolic flux through the GABA shunt, suggesting that this pathway can indeed provide an alternative to the thiamin-dependent oxidative decarboxylation of 2-oxoglutarate, to maintain energy-yielding metabolism in thiamin deficiency.

Increased metabolic flux through GABA may explain the well-established anorexia associated with thiamin deficiency. In experimental animals, increased GABA flux in the ventro-lateral hypothalamus inhibits feeding (Kimura \& Kuriyama, 1975; Kasser et al. 1985). A relatively specific inhibitor of GABA aminotransferase, 1-(n-decyl)-3-pyrazolidine, which causes a threefold increase in brain GABA content in rats, causes marked anorexia (White et al. 1982).

M.G.P. was an SERC student; V.A.-S. was supported by the British Council and the Government of Ghana.

\section{REFERENCES}

Bergmeyer, H. U. \& Bernt, E. (1974). $\alpha$-Keto-glutarate: ultraviolet spectrophotometric determination. In Methods in Enzymatic Analysis, vol. 3, pp. 1624-1627 [H. U. Bergmeyer, editor]. New York and London: Academic Press.

Brin, M. (1967). Functional evaluation of nutritional status: thiamine. In Newer Methods of Nutritional Biochemistry, pp. 407-445 [A. A. Albanese, editor]. New York and London: Academic Press.

Butterworth, R. F. (1983). Amino acid neurotransmitter function in thiamine deficiency encephalopathy. Journal of Neurochemistry 41, Suppl. S31/D.

Collins, R. C., Kirkpatrick, J. B. \& McDougal, D. B. (1970). Some regional pathological and metabolic consequences in mouse brain of pyrithiamine-induced thiamine deficiency. Journal of Neuropathology and Experimental Neurology 29, 57-69. 
Dreyfus, P. M. \& Hauser, G. (1965). The effect of thiamin deficiency on the pyruvate decarboxylase system of the cns. Biochimica et Biophysica Acta 104, 78-84.

Gibson, G., Ksiezak-Reding, H., Shen, K., Mykytyn, B. \& Blass, J. (1984). Correlation of enzymatic, metabolic and behavioural deficits in thiamin deficiency and its reversal. Neurochemical Research 9, 803-814.

Gubler, C. J., Adams, B. L., Hammond, B., Chuan-Yuan, E., Guo, S. T. I. \& Bennion, M. (1974). Effect of thiamin deprivation and thiamin antagonists on the level of aminobutyric acid and on 2-oxo-glutarate metabolism in rat brain. Journal of Neurochemistry 22, 831-836.

Hamel, E., Butterworth, R. F. \& Barbeau, A. (1979). Effect of thiamine deficiency on levels of putative amino acid neurotransmitters in affected regions of rat brain. Journal of Neurochemistry 33, 575-577.

Hearl, W. \& Churchich, J. (1984). Interactions between 4-aminobutyrate aminotransferase and succinic semialdehyde dehydrogenase, two mitochondrial enzymes. Journal of Biological Chemistry 259, 11459-11463.

Holowack, J., Kaufmann, F., Ikossi, M. G., Thomas, C. \& McDougal, D. B. (1968). The effects of a thiamine antagonist, pyrithiamine, on levels of selected metabolic intermediates and activities of thiamine dependent enzymes in brain and liver. Journal of Neurochemistry 15, 621-631.

Jaworek, D., Gruber, W. \& Bergmeyer, H. U. (1974). Adenosine-5-triphosphate: determination with 3phosphoglyceric acid kinase. In Methods in Enzymatic Analysis, vol. 4, pp. 2097-2101 [H. U. Bergmeyer, editor]. New York and London: Academic Press.

Kasser, T., Harris, R. \& Martin, R. (1985). Levels of satiety: GABA and pentose shunt activities in three brain sites associated with feeding. American Journal of Physiology 248, R453-R458.

Kimura, H. \& Kuriyama, K. (1975). Distribution of $\gamma$-aminobutyric acid in the rat hypothalamus: functional correlates of GABA with activities of appetite controlling mechanisms. Journal of Neurochemistry 24, $903-907$.

McCandless, D. W., Carley, A. D. \& Cassidy, C. E. (1976). Thiamine deficiency and the pentose phosphate pathway in rats: intracerebral mechanisms. Journal of Nutrition 106, 1144-1151.

McCandless, D. W. \& Schenker, S. (1968). Encephalopathy of thiamine deficiency; studies of intracerebral mechanisms. Journal of Clinical Investigation 47, $2268-2280$.

McKhann, G. \& Towers, D. (1961). The regulation of $\gamma$-aminobutyric acid metabolism in cerebral cortex mitochondria. Journal of Neurochemistry 7, 26-32.

Oser, B. L. (1965). Hawk's Physiological Chemistry, p. 1096. New York: McGraw-Hill.

Parker, W., Hass, R., Stumpf, D., Parks, J., Eguren, L. \& Jackson, C. (1984). Brain mitochondrial metabolism in experimental thiamine deficiency. Neurology 34, 1477-1481.

Porter, T. \& Martin, D. (1984). Evidence for feedback regulation of glutamate decarboxylase by $\gamma$-aminobutyric acid. Journal of Neurochemistry 43, 1464-1467.

Porter, T., Martin, S. \& Martin, D. (1986). Activation of glutamate apo-decarboxylase by succinic semi-aldehyde and PMP. Journal of Neurochemistry 47, 468-471.

Rozanov, V.A. (1982). Seasonal changes in the $\gamma$-aminobutyric acid system of the mouse brain. Ukrayins'kyi Biokhemichnyi Zhurnal 54, 36-40.

Schousboe, A. (1981). Transport and metabolism of glutamate and GABA in neurons and glial cells. International Review of Neurobiology 22, 1-45.

Udenfriend, S. (1962). Fluorescence Assay in Biology and Medicine, pp. 233-236. New York: Academic Press.

van der Heyden, J., de Kloet, E. \& Versteeg, D. (1979). GABA content of discrete brain nuclei and spinal cord of the rat. Journal of Neurochemistry 33,857-861.

van der Heyden, J. \& Korf, J. (1978). Regional levels of GABA in the brain: rapid semi-automated method and prevention of post-mortem increase by 3-mercapto-propionic acid. Journal of Neurochemistry 31, $197-203$.

Waynforth, H. B. (1980). Experimental and Surgical Techniques in the Rat, pp. 34-36. London: Academic Press.

White, H. L., Howard, J. L., Cooper, B. R., Soroko, F. E., McDermid, J. D., Ingold, K. J. \& Maxwell, R. A. (1982). A novel inhibitor of $\gamma$-aminobutyrate aminotransferase with anorectic activity. Journal of Neurochemistry 39, 271-273.

Wirz-Justice, A. (1987). Circadian rhythms in mammalian neurotransmitter receptors. Progress in Neurobiology 29, 219-259. 